\title{
Mean Residence Time
}

National Cancer Institute

\section{Source}

National Cancer Institute. Mean Residence Time. NCI Thesaurus. Code C85535.

The average time that an exogenous compound resides in the body. 